\title{
The Role of Tibialis Anterior Tendon Transfer in Relapsed Congenital Clubfoot
}

M.M.El-Sayed, G.A.Hosny, A.S.El-Gazzar and E.E.Othman

Orthopedic Surgery Dept., Faculty of Medicine, Benha Univ., Benha, Egypt

\begin{abstract}
E-Mail:E.Othman6@gmail.com
\section{Abstract}

The Ponseti technique to treat idiopathic clubfoot had great outcomes in both present moment and long haul subsequent meet-ups. The point of this forthcoming investigation was to assess the outcomes after tibialis foremost ligament move activity in patients with backslid intrinsic clubfeet. Forthcoming investigation on twenty idiopathic club feet treated by TATT to the horizontal cuniform to address dynamic supination or backslides in more established matured patients after amendment of the deformation by control by Ponseti strategy with follow up for twelve month.In this arrangement $18 / 20$ patients $(90 \%)$ that created backslides of club foot after remedy by Ponseti technique were rebellious with the Foot Abduction Orthosis (FAO) routine and 2/20 patients (10\%) were agre eable with late evening propping. All out tibialis front ligament move is a protected method for amendment of lingering dynamic supination disfigurement.
\end{abstract}

\section{Introduction}

Innate talipes equinovarus (CTEV) or clubfoot is one of the most widely recognized pediatric foot disfigurement happens at 1 of every 1000 live births $[1,2]$ The reason for innate clubfoot is obscure. Different hypotheses have been proposed including vascular, viral, hereditary, anatomical, following a compartment disorder, natural elements and the impact of the situation in utero [2].

Clubfoot comprises of four parts: lower leg equinus, hindfoot varus, forefoot adductus, and midfoot cavus [3-6] Although, there are various traditionalist or non-moderate medicines have been utilized to address the clubfoot, it is as yet testing to treat the most serious instances of clubfoot.

Throughout the previous 150 years, the treatment strategies utilized for clubfoot are still controversial [7] Because, the broad surgeries (rehashed delicate tissue discharges) on the clubfoot lead to incite a few difficulties, for example, solidness of foot, joint issues and low quality of life [8]. After that, various moderate techniques are proposed to address the clubfoot deformation with the accompanying procedures, for example, various techniques for controls, orthosis or supporting or propping, projecting, and lashing [9-11].

Truly, traditionalist administration was presented by Hippocrates in around 400 BC [12-14]. Later, in 1939, Kite presented his method,(14) alluded as Kite strategy, which is including control and projecting procedure, however the achievement pace of this technique was poor $[7,10,15]$.

Along these lines, in 1963, Ponseti built up a moderate technique, called as Ponseti strategy, with control, projecting, Achilles tenotomy and propping, and it takes around four to five weeks to accomplish the full rectification of every one of the four segments of the clubfoot deformation [16, 17]. In this strategy, Achilles tenotomy is utilized to deliver the equinus deformation and preparing for keeping up the amended clubfoot, [18, 19] and it assists with acquiring the plantigrade, useful, torment free foot [20].
It is notable that inborn clubfoot may backslide paying little heed to the treatment given and the ampleness of the rectification accomplished. Indeed, a few creators have announced a high rate of backslide even in innate clubfeet that had been completely remedied since the primary month of life [21].

Backslid clubfoot disfigurement might be because of deficient essential remedy, loss of decrease, scarring, muscle unevenness or the first pathology [22]. As various distortions might be available, an extensive careful methodology is required, customized to the deformation and the age of the youngster [23].

Careful methods for backslid intrinsic clubfeet can be separated into three general classifications specifically delicate tissue discharges, hard techniques and ligament moves, the previous two speaking to the principle restorative strategies [24]. Tendon exchanges assume an optional job and are demonstrated when muscle awkwardness is a twisting or irritating factor [25].

Tibialis front ligament move is important for the Ponseti the board for inherent clubfoot, which, when shown, looks to diminish the probability of future repeat of the deformation [26]. The choice to suggest a medical procedure is mentioned by objective fact of kids have feet that supinate during the swing stage and are supinated somewhat in the position stage, yet which are completely correctable at static assessment, [27] and a physically tried awkwardness among reversal and eversion strength [28].

The point of this imminent investigation was to assess the outcomes after tibialis front ligament move activity in patients with backslid inherent clubfeet.

\section{Patient and method}

Prospective study on twenty idiopathic club feet treated by TATT to the lateral cuniform to correct dynamic supination or relapses in older aged patients after correction of the deformity by manipulation by Ponseti technique with follow up for twelve month. 


\section{Inclusion criteria}

Dynamic supination in club feet after correction by Ponseti method with callosities over the lateral border of the foot. plus or minus tendoachilis shortening. 2Multiple relapses of clubfeet after correction by Ponseti in patient older than two and half years after correction of the deformity by reapplication of Ponseti method.

\section{Exclusion criteria}

1-Neuropathic club foot.

2-Corrected club foot after surgical release.

3-Patient age less than three years.

4- Tibialis anterior muscle weakness.

\section{Protocol of management}

1- TATT for patients with only dynamic supination and callosities over the lateral part of the sole.

2- TATT and tendoachilis lengthening in presence of additional short tendon achilis, and plantar release in tight planter fascia and medial release done for tight medial soft tissue.

\section{Results}

Average age of patients was four years and one month and $14(70 \%)$ of them were males. In this study, Clubfoot recurrence took place most frequently between three and five years of age $(90 \%)$.

six patients were suffered from idiopathic club foot in the right, 2(10\%) were left and $12(60 \%)$ were bilateral

Dennis brown Duration was $2.07 \pm 0.584$ while preoperative Pain was obtained in $5(25 \%)$ and preoperative cast was done in 5 (25\%)patients

Preoperative Pre-operative (Plt and INR) were in normal range in average with mild hypochromic anemia in average $(\mathrm{Hb}=11.06 \mathrm{~g} / \mathrm{dl})$

After three months of surgery, all patient were with Neutral heel without any deformity but after 6 monthes, $14(70 \%)$ of them developed Valgus heel while after one year, Only two patients $(10 \%)$ had developed heel varus and needed further correction
Two patients (10\%) developed Early heel rise after 6 months. undiagnosed neuromuscular disorders may have been the cause for relapse after tibialis anterior tendon transfer but were not identified in either of these patients.

After 6 months, Two patients (10\%) developed metatarsus adduction

According to post-operative follow-up of Standing supination, we obtained that $8(40 \%)$ suffered from Standing supination before surgery which is resolved in 6 of them and only 2 patient (10\%) from developed Standing supination .

While all patients were suffering from preoperative walking supination Two patients (10\%) developed walking supination after 6 monthes and 1 year

Eighteen patients $(90 \%)$ were considered to have a normal appearance of feet which is plantigrade feet, no walking supination, no standing supination, no metatrsus adductus, nor heel varus except for the surgical scar

The range of active ankle dorsiflexion was improved in average from 3.25 to 9.0 after even 6 month and 1 year followup

In this series, from history $18 / 20$ patients (90\%) that developed relapses of club foot after correction by Ponseti method were noncompliant with the Foot Abduction Orthosis (FAO) regimen and 2/20 patients $(10 \%)$ were compliant with night bracing .

Additional procedures were done for some patients based on the preoperative clinical and radiographic assessment of the feet and included plantar release done for four patients (20\%), posterior release done for four patients (20\%), medial release done for four patients $(20 \%)$.

Ten patients $(50 \%)$ need physiotherapy post operative for improvement of range of motion of ankle and subtalar joints and improvement of foot muscle strength

One case $(5 \%)$ developed superficial infection in the sole of the foot. Another case $(5 \%)$ presented by raw area at the sole of the foot that subsided after three weeks by medical treatment

Table (1) Basal and post-operative follow-up of plantigrade foot in the studied patients.

\begin{tabular}{lccc}
\hline Basal & 12 & $60 \%$ & - \\
\hline Three months & 20 & $100 \%$ & 0.046 \\
Six months & 18 & $90 \%$ & 0.157 \\
One year & 18 & $90 \%$ & 1 \\
Data is expressed as percentage and frequency. P value is generated by \\
comparing each reading to the basal value. P is significant when $<\mathbf{0 . 0 5}$.
\end{tabular}

Table (2) Basal and post-operative follow-up of active ankle dorsiflexion in the studied patients.

\begin{tabular}{llc}
\hline Basal & $3.25 \pm 2.447$ & - \\
\hline Three months & $4.5 \pm 1.539$ & 0.025 \\
Six months & $9.0 \pm 2.052$ & $<0.001$ \\
One year & $9.0 \pm 3.078$ & $<0.001$
\end{tabular}

Data is expressed as percentage and frequency. $P$ value is generated by comparing each reading to the basal value. $P$ is significant when $<0.05$ 
Table (3) Motor strengthof TA at FU in the studied patients.

\begin{tabular}{llll}
\hline & Good & 18 & $90 \%$ \\
\cline { 2 - 4 } Motorstrength of TA at FU & Fair & 2 & $10 \%$ \\
& Poor & 0 & $0 \%$ \\
Data is expressed as percentage and frequency. P value is generated by \\
comparing each reading to the basal value. P is significant when $<\mathbf{0 . 0 5}$. \\
\hline
\end{tabular}

Table (4) Associated releaseand post-operative course in the studied patients.

\begin{tabular}{lrc}
\hline Med release & $\mathbf{6}$ & $\mathbf{3 0 \%}$ \\
\hline Post release & 4 & $20 \%$ \\
Planter release & 5 & $25 \%$ \\
complication & 2 & $10 \%$ \\
physiotherapy & 8 & $40 \%$ \\
Data is expressed as percentage and frequency \\
\hline
\end{tabular}

\section{Discussion}

Regardless of the best exertion, repeats of CTEV do happen. Empowering the guardians or watchmen and parental figures to hold fast to the FAB convention could bring down the opportunity of recurrences [29] A day by day physiotherapy program assistant to the Ponseti technique shows an improvement of the Dimeglio scores [30].

Backslide is regularly successfully and effectively treatable when found at a beginning phase. Generally, this is seen when guardians are resistant with the Foot Abduction Orthosis (FAO) routine, and the impact point sneaks out of the shoe. The standards for restorative moves are equivalent to for the first treatment [31]. Two or three rehashed castings, with as long as fourteen day spans, are normally expected to address the varus position of the impact point and forefoot adduction. A percutaneous Achilles ligament stretching can be performed as long as one year old enough, in spite of the fact that the upper age limit for this system is obscure. The moving around kid with dynamic supination, and a completely remedied foot at static assessment, can be treated with front tibial ligament move [32].

The dynamic forefoot distortion was seen after clubfoot treatment with or without delicate tissue discharges. The forefoot deformations comprised of adduction and supination. The dynamic disfigurement should be separated from an unbending distortion, which regularly came about because of hard deformation or joint contracture [28]. This disfigurement came about because of a solid tibialis foremost muscle and feeble adversaries, especially the peroneal and tibialis back muscles. It is likewise a typical sequelae following in any case fruitful nonoperative treatment with the Ponseti technique [109, 162].

The exchange of the ligament of tibialis front is a significant piece of the Ponseti technique for the treatment of backsliding clubfeet [29] and is demonstrated to be a sensible methods for accomplishing balance and forestalling the movement of deformity [33]. In these cases, this exchange, generally proceeded as a separated methodology, requires early acknowledgment of repetitive deformity [29] and an adaptable foot ([34].

In this investigation, the complete exchange of the foremost tibial ligament was done to the third cuneiform, under the extensor retinaculum. The activity was performed through two cut as Ponseti procedure.

This investigation report a year forthcoming clinical preliminary assessing the results of twenty kids with intrinsic talipes equinovarus going through tibialis front ligament move. This Patients indicated dynamic lopsidedness and diminished capacity before medical procedure. At a year, muscle offset reestablished with great capacity. Diligent contrasts in foot arrangement and inactive scope of development, and documentation of two repeats, recommend that a basic distortion might be available in this populace. Bigger forthcoming preliminaries utilizing dependable and substantial result measures are needed to precisely report mid-and long haul results of this populace.

There are a few impediments to this examination. To start with, our preliminary is restricted by little patient numbers; bigger preliminaries will improve accuracy of the findings. Second, the year follow up probably won't have caught all repeats; longer subsequent will be significant. Third, albeit all patients revealed consistence with the Ponseti method, this can't be unbiasedly confirmed.

At long last correlation between this investigation and others was troublesome in light of the fact that accessible information too short and their boundaries in evaluation were not the same as those in this examination.

\section{References}

[1] M.B.Dobbs, C.A.Gurnett. Update on Clubfoot: Etiology and Treatment. Clinical Orthopaedics and Related Research.Vol.467(5),PP.1146-53,2009.

[2] R.Wynne-Davies .Family studies and the cause of congenital club foot. The Journal of bone joint surgery British volume.Vol.46(3),PP.445-63,1964.

[3] I.V.Ponseti. Congenital clubfoot. Fundamentals of treatment.Vol.5,PP.37-48,1996. 
[4] G.W.Simons, S.Sarrafian. The Microsurgical Dissection of a Stillborn Fetal Clubfoot. Clinical Orthopaedics and Related Research.Vol.\&NA (173),PP.275-83,1983.

[5] D.W.McKay. New Concept of and Approach to Clubfoot Treatment. Journal of Pediatric Orthopaedics.Vol.2(4),PP.347-56,1982.

[6] R.N.Irani, M.S.Sherman. The Pathological Anatomy of Club Foot. The Journal of Bone \& Joint Surgery.Vol.45(1),PP.45-52,1963.

[7] I.V.Ponseti. Treatment of congenital club foot. The Journal of Bone \& Joint Surgery.Vol.74(3),PP.448-54,1992.

[8] M.B.Dobbs, R.Nunley, P.L.Schoenecker. Longterm follow-up of patients with clubfeet treated with extensive soft-tissue release. JBJS.;88(5):98696.

[9] Turco VJ. Surgical Correction of the Resistant Club Foot. The Journal of Bone \& Joint Surgery.Vol.53(3),PP.477-97,1971.

[10] J.Hiram Kite. Nonoperative Treatment of Congenital Clubfoot. Clinical Orthopaedics and Related Research.Vol.84,PP.29-38,1972.

[11]D.W.McKay. New Concept of and Approach to Clubfoot Treatment. Journal of Pediatric Orthopaedics.Vol.3(1),PP.10-21,1983.

[12]E.H.Strach. Club-foot Through the Centuries. Historical Aspects of Pediatric Surgery: Springer Berlin Heidelberg.Vol.5,pp 215-37,1986.

[13] V.Turco, A.Spinella. Current management of clubfoot. Instructional course lectures.Vol.31,PP.218,1982.

[14] J.Kite. Principles involved in the treatment of congenital club-foot. JBJS.Vol.21(3),PP.595$606,1939$.

[15] J.E.Herzenberg, C.Radler, N.Bor. Ponseti Versus Traditional Methods of Casting for Idiopathic Clubfoot. Journal of Pediatric Orthopaedics.Vol.22(4),PP.517-21,2002.

[16] I.V.Ponseti, E.N.Smoley. Congenital Club Foot. The Journal of Bone \& Joint Surgery.Vol.45(2),PP.261-344,1963.

[17] J.A.Morcuende, D.Abbasi, L.A.Dolan, I.V.Ponseti. Results of an Accelerated Ponseti Protocol for Clubfoot. Journal of Pediatric Orthopaedics.Vol.25(5),PP.623-6,2005.

[18] D.M.Cooper, F.R Dietz. Treatment of idiopathic clubfoot. A thirty-year follow-up note. The Journal of bone joint surgery American volume.Vol.77(10),PP.1477-89,1995.

[19] S.J.Laaveg, Ponseti IV. Long-term results of treatment of congenital club foot. The Journal of bone joint surgery American volume.Vol.62(1),PP.23-31,1980.

[20] D.I.Cosma, D.E.Vasilescu. Ponseti treatment for clubfoot in Romania. Journal of Pediatric Orthopaedics B.Vol.23(6),PP.512-6,2014.

[21]P.Farsetti, R.Caterini, F.Mancini. Anterior tibial tendon transfer in relapsing congenital clubfoot: long-term follow-up study of two series treated with a different protocol. Journal of Pediatric Orthopaedics B.Vol.26(1),PP.83-90, 2006.

[22] S.S.Park, S.W.Kim, B.S.Jung, H.S.Lee. Selective soft-tissue release for recurrent or residual deformity after conservative treatment of idiopathic clubfoot. The Journal of Bone and Joint Surgery British volume.Vol.91-B(11),PP.152630,2009 .

[23] K.N.Kuo, P.A.Smith. Correcting Residual Deformity Following Clubfoot Releases. Clinical Orthopaedics and Related Research.Vol.467(5),PP.1326-33,2008.

[24] M.Lampasi, C.Bettuzzi, M.Palmonari. Transfer of the tendon of tibialis anterior in relapsed congenital clubfoot: long-term results in 38 feet. The Journal of bone joint surgery British volume.Vol.92(2),PP.277-83,2010.

[25] G.H.Thompson, H.A.Hoyen, T.Barthel. Tibialis anterior tendon transfer after clubfoot surgery. Clinical orthopaedics related research.Vol.467(5),PP.1306-13,2009.

[26] K.Z .Masrouha, J.A.Morcuende. Relapse after tibialis anterior tendon transfer in idiopathic clubfoot treated by the Ponseti method. Journal of Pediatric Orthopaedics B.Vol.32(1),PP.81-4,2012.

[27]E.Ezra, S. Hayek, A.N Gilai, O.Khermosh. Tibialis anterior tendon transfer for residual dynamic supination deformity in treated club feet. Journal of pediatric orthopedics Part B.Vol.9(3),PP.207-11, 2000.

[28] K.N.Kuo, S.P.Hennigan, M.E.Hastings. Anterior Tibial Tendon Transfer in Residual Dynamic Clubfoot Deformity. Journal of Pediatric Orthopaedics. Vol.21(1),PP.35-41,2001.

[29] N.H.Miller, P.M.Carry, B.J.Mark. Does Strict Adherence to the Ponseti Method Improve Isolated Clubfoot Treatment Outcomes? A Two-institution Review. Clinical Orthopaedics and Related Research.Vol.474(1),PP.237-43,2015.

[30] B.Nilgün, E.Suat, Ş.İ.Engin. Short-term results of intensive physiotherapy in clubfoot deformity treated with the Ponseti method. Pediatrics International.Vol.53(3),PP.381-5,2011.

[31]F.Dietz. Treatment of a recurrent clubfoot deformity after initial correction with the Ponseti technique. Instructional course lectures.Vol.55,PP.625-9,2006.

[32] J.A.Morcuende, L.A.Dolan, F.R.Dietz. Radical reduction in the rate of extensive corrective surgery for clubfoot using the Ponseti method. Pediatrics.Vol.113(2),PP.376-80,2004.

[33] I.V.Ponseti, J.Campos. Observations on pathogenesis and treatment of congenital clubfoot. Clinical Orthopaedics Related Research.Vol.84,PP.50-60,1972.

[34] K.N.Kuo, P.A.Smith. Correcting residual deformity following clubfoot releases. Clinical orthopaedics related research.Vol.467(5),PP.132633,2009 . 